\section{S136 MTOR SIGNALLING IS AN ESSENTIAL PATHWAY FOR TGF- $\beta 1$ INDUCED $\alpha$ SMA AND COLLAGEN GENE EXPRESSION}

${ }^{1} \mathrm{HV}$ Woodcock, ${ }^{2} \mathrm{~S}$ Peace, ${ }^{2} \mathrm{CB}$ Nanthakumar, ${ }^{1} \mathrm{TM}$ Maher, ${ }^{1} \mathrm{PF}$ Mercer, ${ }^{1} \mathrm{RC}$ Chambers. ${ }^{1}$ Centre for Inflammation and Tissue Repair, UCL, London, UK; ${ }^{2}$ GlaxoSmithKline $R$ and $D$, Stevenage, UK

10.1136/thoraxjnl-2014-206260.142

Emerging evidence suggests a role for $\mathrm{PI} 3 \mathrm{~K} / \mathrm{mTOR}$ signalling in the pathology of organ fibrosis. The aim of this study was to delineate PI3K/mTOR signalling in response to TGF- $\beta_{1}$ stimulation of primary human lung fibroblasts (HLFs), and to investigate the role of this pathway in TGF- $\beta_{1}$ mediated myofibroblast differentiation and collagen synthesis.

A time-course of SMAD 2/3 and Akt (Ser473) phosphorylation, the major downstream effector of the PI3K/mTOR pathway, was constructed to assess TGF- $\beta_{1}$ induced signalling kinetics in HLFs. TGF- $\beta_{1}(1 \mathrm{ng} / \mathrm{ml})$ induced rapid phosphorylation of SMAD2/3, peaking at $1 \mathrm{~h}$, followed by Akt phosphorylation which peaked $12 \mathrm{~h}$ after initial stimulation. Maximal expression of ACTA2 and COL1A1 was observed $36 \mathrm{~h}$ after TGF- $\beta_{1}$ stimulation, correlating with the delayed time-course of Akt phosphorylation.

To investigate the role of the PI3K/mTOR pathway in TGF$\beta_{1}$ induced myofibroblast differentiation and collagen gene expression, HLFs were treated with pharmacological titrations of potent pathway inhibitors. Maximal Akt signalling and expression of ACTA2 and COL1A1 were significantly inhibited by a dual PI3K/mTOR inhibitor, while SMAD phosphorylation was unaffected. Treatment with an ATP competitive mTOR inhibitor also resulted in significantly reduced Akt phosphorylation and expression of ACTA2 and COL1A1, in response to TGF- $\beta_{1}$. In contrast, treatment of HLFs with either an allosteric or ATP competitive Akt inhibitor showed no inhibitory effect on TGF- $\beta_{1}$ induced gene expression.

These data suggest PI3 kinase/mTOR signalling is an important component in TGF- $\beta_{1}$ induced $\alpha$ SMA and collagen gene expression and that an mTOR dependent, Akt independent pathway mediates this functional response in primary HLFs.

\section{S137 VASCULAR ENDOTHELIAL GROWTH FACTOR (VEGF) EXPRESSION IN THE IPF LUNG - A ROLE FOR ANTI- ANGIOGENIC ISOFORMS?}

${ }^{1} \mathrm{SL}$ Barratt, ${ }^{1} \mathrm{~T}$ Blythe, ${ }^{1} \mathrm{C}$ Jarrett, ${ }^{1} \mathrm{G}$ W Welsh, ${ }^{1} \mathrm{~K}$ Ourradi, ${ }^{2} \mathrm{C}$ Scotton, ${ }^{3} \mathrm{DO}$ Bates, ${ }^{1} \mathrm{AB}$ Millar. ${ }^{1}$ School of Clinical Sciences, University of Bristol, Bristol, UK; ${ }^{2}$ University of Exeter, Exeter, UK; ${ }^{3}$ University of Nottingham, Nottingham, UK

\subsection{6/thoraxjnl-2014-206260.143}

Introduction VEGF has been implicated in the pathogenesis of IPF. Differential splicing of the VEGF gene produces an alternative family of isoforms $\left(\mathrm{VEGF}_{\mathrm{xxx}} \mathrm{b}\right)$ that have anti-angiogenic properties, in contrast to conventional isoforms $\left(\mathrm{VEGF}_{\mathrm{xxx}}\right)$. Currently available literature on the role of VEGF in IPF has not differentiated between these families of isoforms and thus a degree of literature re-appraisal is required.

Hypotheses

- The balance of $\mathrm{VEGF}_{\mathrm{xxx}}: \mathrm{VEGF}_{\mathrm{xxx}} \mathrm{b}$ isoforms may be important in IPF pathogenesis

- $\mathrm{VEGF}_{\mathrm{xxx}} \mathrm{b}$ isoforms may abrogate the development of IPF

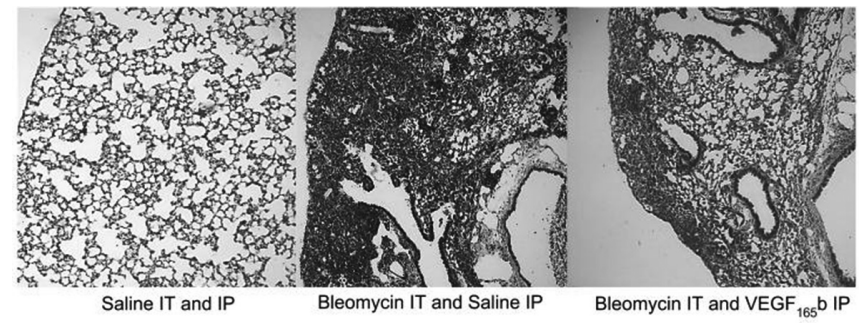

Abstract S137 Figure 1 The effect of VEGF 165 b on the development of murine BLM-induced pulmonary fibrosis

Bleomycin was given to WT type mice ( $n=6$ per group) by oro-pharyngeal aspiration (Day 0). rhVEGF $165 \mathrm{~b}$ was administered by IP injection $(1 \mu \mathrm{g}$ per mouse, bi-weekly) from days 10 to 21. Fibrosis was scored and examined histologically by Masson's trichrome staining. The development of BLM-induced fibrosis was attenuated in mice receiving rhVEGF $_{165} \mathrm{~b}$

Methods Human lung sections and BALF were used to quantify isoform expression in the IPF lung and were compared to controls (ELISA and IHC). Explanted 'normal' (NF) and 'fibrotic' (FF) fibroblasts were grown in culture with subsequent total RNA and cell lysate extraction (qPCR and WB). Wild-type mice were administered bleomycin (BLM) then received bi-weekly therapeutic intraperitoneal (IP) injections of $\mathrm{rhVEGF}_{165} \mathrm{~b}$ (from day 10). Fibrosis was assessed histologically (Masson's Trichrome and Lung fibrosis score).

Results In the IPF lung, the alveolar epithelium was the most prominent site for total VEGF (PanVEGF isoforms) but also for $\operatorname{VEGF}_{165} \mathrm{~b}(\mathrm{n}=10)$. Addiitonal staining was noted in fibroblasts and lung inflammatory cells. Alveolar and fibrotic cells in the least fibrotic areas of the IPF lung expressed significantly less VEGF $_{165} \mathrm{~b}$ than severely fibrotic areas $(\mathrm{p}<0.001, \mathrm{n}=10)$. Examination of IPF BALF by ELISA revealed that total VEGF expression was significantly lower compared to control (IPF: $18.04 \mathrm{pg} / \mathrm{ml}+/-6.13 \mathrm{n}=15$, CTRL $85.72 \mathrm{pg} / \mathrm{ml}+/-17.08$ $\mathrm{n}=13$ ), whilst $\mathrm{VEGF}_{165} \mathrm{~b}$ could not be detected in identical samples.

Explanted NF and FF express comparable quantities of $\mathrm{VEGF}_{\mathrm{xxx}}$ and $\mathrm{VEGF}_{\mathrm{xxx}} \mathrm{b}$ isoforms at the mRNA and protein level. Rh $\mathrm{VEGF}_{165}$ increases the mRNA expression of fibronectin $(\mathrm{p}<0.001, \mathrm{n}=4)$ an effect not seen following the administration of rhVEGF $_{165} \mathrm{~b}$.

Administration of $\operatorname{rhVEGF}_{165} \mathrm{~b}$ to mice attenuated the development of BLM-induced pulmonary fibrosis (Masson's Trichrome (Figure 1) and lung fibrosis score (mean score: BLM alone 41.20 vs $\mathrm{VEGF}_{165} \mathrm{~b} 30.67, \mathrm{p}<0.01, \mathrm{n}=6$ per group)). Conclusion Differential expression of $\mathrm{VEGF}_{\mathrm{xxx}}$ and $\mathrm{VEGF}_{\mathrm{xxx}} \mathrm{b}$ isoforms occurs in the IPF lung. In vitro, recombinant proteins appear to have differential effects on ECM synthesis and in vivo attenuate the formation of pulmonary fibrosis. A mouse overexpressing VEGF $_{165} \mathrm{~b}$ in the lung has been developed to study this concept in greater detail.

\section{S138 NANODIAMOND DELIVERY OF VASCULAR ENDOTHELIAL GROWTH FACTOR PROMOTES FETAL LUNG DEVELOPMENT IN A RAT MODEL OF CONGENITAL DIAPHRAGMATIC HERNIA}

${ }^{1} \mathrm{~N}$ Al-Juffali, 'S Loukogeorgakis, ${ }^{2} \mathrm{~J}$ Jimenez, ${ }^{1} \mathrm{P}$ Maghsoudlou, ${ }^{3} \mathrm{~J}$ Toolen, ${ }^{4} \mathrm{P}$ Carmeliet, ${ }^{3}$ J Deprest, ${ }^{5} \mathrm{P}$ De Coppi, ${ }^{1} \mathrm{~S}$ Janes. ${ }^{1}$ University College London, London, UK; ${ }^{2}$ University of Leuven, Leuven, Belgium; ${ }^{3}$ University Hospitals Leuven, Leuven, Belgium; ${ }^{4}$ VIB Vesalius Research Center, Leuven, Belgium; ${ }^{5}$ Great Ormond Street Hospital for Children NHS Foundation Trust, London, UK

10.1136/thoraxjn-2014-206260.144 